\title{
Consensus on Postoperative Recommendations After Transsphenoidal Surgery
}

\section{A Study Among Pituitary Surgeons in Germany and Review of Literature}

\author{
Authors \\ Ulrich J. Knappe , Dag Moskopp², Rüdiger Gerlach³, Jens Conrad4, Jörg Flitsch ${ }^{5}$, Jürgen B. Honegger ${ }^{\text {* }}$
}

\section{Affiliations}

1 Department of Neurosurgery, Johannes Wesling Klinikum, University Hospital of Ruhruniversität Bochum, Minden

2 Department of Neurosurgery, Vivantes Klinikum Friedrichshain, Berlin

3 Department of Neurosurgery, Helios Kliniken, Erfurt

4 Department of Neurosurgery, Johannes Gutenberg Universität, Mainz

5 Department of Neurosurgery, Universitätskrankenhaus Eppendorf, Hamburg

6 Department of Neurosurgery, Universitätsklinikum Tübingen, Germany

\section{Key words}

pituitary tumor, transsphenoidal surgery, postoperative recommendations

$$
\begin{array}{lr}
\text { received } & 16.05 .2018 \\
\text { revised } & 15.07 .2018 \\
\text { accepted } & 26.07 .2018
\end{array}
$$

\section{Bibliography}

DOI https://doi.org/10.1055/a-0664-7710

Published online: 21.8.2018

Exp Clin Endocrinol Diabetes 2019; 127: 29-36

(c) J. A. Barth Verlag in Georg Thieme Verlag KG Stuttgart . New York

ISSN 0947-7349

\section{Correspondence}

PD Dr. med. Ulrich J. Knappe

Department of Neurosurgery

Johannes Wesling Klinikum

Universitätsklinikum der Ruhruniversität Bochum (RUB)

Hans Nolte Str. 1

32429 Minden

Germany

Tel.: +49/571/790 53301 , Fax: +49/571/790 293300

ulrich.knappe@rub.de $\circledast$ AGREE Reporting Checklist 2016 Online content viewable at https://doi.org/10.1055/a-0664-7710

\section{ABSTRACT}

Background Guidelines for patient behavior following transsphenoidal surgery do not exist. To gain generally recommendations, the German pituitary working group conducted a study among pituitary surgeons to elucidate their opinions and customs of patients' counselling.

Methods Questions concerning daily activities, exertion of sports and work life were addressed. It was asked to provide the postoperative time interval after which specific activities can be resumed both after a routine or an extended approach. Results Fourteen pituitary surgeons returned the completed questionnaire. Following routine operations, washing the hair was allowed within one week, blowing the nose after 3, flying on an airplane and driving a car after one, lifting heavy weights after 4 , playing wind instruments after 6 , use of CPAP (continuous positive airway pressure) device after 3 , permit leisure sports after 2 to 4 weeks (except for scuba diving). Competitive sports can be resumed after 6 weeks. Occupation with mental demands was considered feasible after 2 weeks, with physical labor after 4 weeks. After extended transsphenoidal surgery, the recommended time interval was roughly twice as long compared to the routine approach. Driving a car was allowed within the first 4 weeks after surgery by some pituitary surgeons, while others allow driving only after 3 months analogous to the regulations after craniotomy. The risk of scuba diving was considered high.

Conclusions The data of our study and the literature, and expert opinions from related scientific fields resulted in a consensus on recommendations for patients' conduct to minimize risks after transsphenoidal surgery. 


\section{Introduction}

For more than 40 years, transsphenoidal surgery (TSS) is the standard approach to treat pituitary adenomas, most craniopharyngiomas, Rathke's cleft cysts and other, less frequent pathologies of the sellar and perisellar region [1]. Nowadays microsurgery as well as endoscopy is used with very good results in experienced hands [2-4]. Although different complications of TSS have been reported, it is considered to be a safe procedure, with the complication rate depending on the surgeons experience [5, 6] (6,9\% major complication, $0,7 \%$ death). However, guidelines for patients `level of activity following TSS do not exist. Therefore, the neurosurgeons of the pituitary study group of the German Society of Endocrinology (DGE) started a nationwide survey of the current practice in counselling their patients postoperatively. Stepwise they came to a consensus statement. The focus of this report is on the advice related to the surgical approach only. The recommendations, however, may differ considerably in individual cases depending on the endocrinological, neurological, and ophthalmological state given.

\section{Subjects and Methods}

The study was initiated by the speaker of the Pituitary Study Group of the German Society of Endocrinology (DGE). A digital questionnaire was sent to 22 German neurosurgeons who are known to be actively involved in pituitary surgery. Fourteen of 22 pituitary surgeons returned the completed questionnaire (64\%), 9 with microsurgical and 5 with endoscopic focus.

The surgeons were asked about their personal experience with rules of conduct for patients following TSS, namely how many transsphenoidal procedures they had performed or supervised in the preceding year (2016), and how many such operations had been performed in their institution in that period. Moreover, the participants were asked to state whether they mainly use the microscope or the endoscope during TSS. Endoscopically assisted microsurgical technique was assumed microscopic.

The queries addressed both a routine transsphenoidal approach and an extended transsphenoidal approach (e.g. transtuberculumsellae or transclival approach). The participants were asked to provide the postoperative time interval after which specific activities could be resumed by their patients. The questions addressed 3 topics: daily activities, exertion of sports and work life.

\section{Daily activities}

washing the hair, nose blowing, sauna, playing wind instruments, flying on an airplane, lifting heavy weights (about $12 \mathrm{~kg}$, assumed equivalent to a crate of mineral water), driving a car, using a CPAP (continuous positive airway pressure) -device, and having sexual intercourse.

\section{Recreation sports}

Nordic walking, jogging, swimming (breaststroke - head above water, and crawl - head under water), scuba diving (snorkeling at the surface assumed to be equivalent to crawling), playing tennis, and playing soccer.

Performing competitive sports.

\section{Work life}

Occupation (for $8 \mathrm{~h}$ per day) with mental demands or physical labor.

\section{Process of study}

Initially, the project was presented and discussed at the meeting of the German pituitary working group. The questionnaire was designed by JBH and UJK and send to the German pituitary surgeons. The results were graphically presented and discussed at a following meeting of the pituitary working group and a core group of pituitary surgeons (authors) was constituted to screen the relevant literature (via PUBMED), and to elucidate related scientific issues of the items. During 3 telephone conferences, joint recommendations were elaborated. The results were brought together in a manuscript which was then presented to all participating neurosurgeons and consultants, asking for approval, to reach the highest possible grade of agreement. All participants and consultants approved the recommendations as described in this manuscript. The manuscript was checked following the AGREE reporting checklist [7] as far as applicable.

\section{Results}

\section{Participants}

Fourteen pituitary surgeons returned the completed questionnaire, 9 of them with microsurgical focus and 5 of them with endoscopic focus. During one year (2016) these surgeons were responsible for 1004 (range 8 to 270, mean 72, median 50) transsphenoidal procedures. Of these, 846 operations have been performed using microscopic technique (range 38 to 270 , mean 94, median 59), 158 using the endoscope (range 8 to 41 , mean 32, median 40). In the institutions of the participants 1060 transsphenoidal operations had been performed in 2016 (range 8 to 286), indicating that most procedures had been performed/supervised by the participating individuals. Consequently, this report reflects the experience with about 1000 transsphenoidal procedures per year.

There was no significant difference of times after which activities could be resumed between surgeons with endoscopic or microsurgical focus (exemplary illustrated in > Fig. 1), however, independent from surgical technique used, some surgeons tended generally to be more offensive, others more cautious.

\section{Recommendations after routine operations}

Daily activities (see Fig. 1)

For nose blowing the answers varied between few days and 8 weeks (median 3 weeks). The authors agreed to use the median of 3 weeks as a common recommendation ( Table $\mathbf{1}$ ). In case of intraoperative CSF-leak, blowing the nose is allowed after 4 weeks.

Washing the hair was unanimously allowed in the first week after surgery. Discussion between the authors revealed, that in case of intraoperative CSF-leak the patients should refrain from bending the head downward during washing the hair for 3 weeks.

Having a sauna was permitted after 1 to 12 weeks (median 4 weeks). Recommendation after discussion: 4 weeks ( $\triangleright$ Table 1 ).

Playing wind instruments was permitted between 3 and 12 weeks postoperatively (median 6 weeks). After discussion with a consultant for music physiology and musician's medicine (EA), 


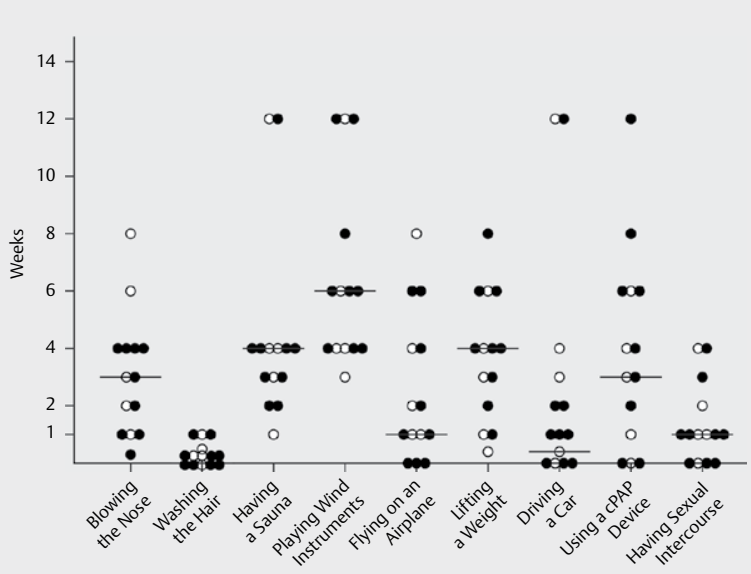

-Fig. 1 The expert opinions of 14 German pituitary surgeons about postoperative daily activities following a routine transsphenoidal procedure are shown. The postoperative time interval after which various daily activities can be resumed is depicted $(\bullet$ or 0 individual answer, - final consensus recommendation). There is no significant difference between recommendations after microsurgical $(\mathrm{N}=9, \bullet)$ or endoscopic $(\mathrm{N}=5, \mathrm{O})$ procedures.
6 weeks could be the starting point of gradual increase in activity (see below).

For flying on an airplane the primary statements varied between a few days and 8 weeks (median 1.5 weeks after surgery). The recommendation of 1 week would allow patient's transfer to motherland after discharge by airplane. Discussion pointed out, that in case of intraoperative CSF-leak absence of free intracranial air is obligatory (e.g. proven by CT-scan).

Lifting a weight was defined as the equivalent to raise a crate of mineral water, which would be at least $12 \mathrm{~kg}$ in Germany. The primary statements varied between a few days and 8 weeks (median 4 weeks), a consensus of 4 weeks was found by the authors.

The majority of pituitary surgeons allowed driving a car early after operation (range a few days to 12 weeks, median 1 week), after discussion between the authors the recommendation was 5 days after surgery. This would allow the patient to drive home by car on discharge. However, two surgeons opted for 12 weeks, following general guidelines of intracranial surgery. For safety reasons, in routine cases also electrolyte imbalance (e. g. hyponatremia) has to be ruled out prior to driving a car.

The results varied considerably concerning the use of a CPAP device (range immediately to 12 weeks, median 3.5 weeks). The

- Table 1 Instructions for patients` behavior after routine transsphenoidal pituitary surgery or extended transsphenoidal approach for perisellar lesions created from statement of 14 pituitary surgeons, who stand for about 1000 transphenoidal operations per year.

\begin{tabular}{|c|c|c|c|c|c|c|}
\hline \multirow[t]{2}{*}{ Activity } & \multicolumn{3}{|c|}{ routine transsphenoidal operation [weeks] } & \multicolumn{3}{|c|}{ extended transsphenoidal approach } \\
\hline & range & median & recommendation & range & median & recommendation \\
\hline \multicolumn{7}{|l|}{ daily activity } \\
\hline blow the nose & $<1-8$ & 3 & $3^{\mathrm{A}}$ & $1-12$ & 4 & $4^{\mathrm{A}}$ \\
\hline wash hair & $<1-1$ & $<1$ & $<1$ & $<1-2$ & $<1$ & $<1$ \\
\hline have a sauna & $1-4$ & 4 & 4 & $2-12$ & 4 & 4 \\
\hline wind instrument & $3-12$ & 6 & $6^{\mathrm{B}}$ & $3-26$ & 8 & $6^{\mathrm{B}}$ \\
\hline fly on airplane & $<1-8$ & 1.5 & $1^{\mathrm{C}}$ & $<1-8$ & 2.5 & $2^{C}$ \\
\hline lift heavy weight & $<1-8$ & 4 & 4 & $1-26$ & 6 & 6 \\
\hline drive car & $<1-12$ & 1 & $<1^{\mathrm{D}}$ & $<1-12$ & 4 & $2^{G}$ \\
\hline use CPAP & $<1-12$ & 3.5 & $3^{\mathrm{A}}$ & $<1-12$ & 4 & $4^{\mathrm{A}}$ \\
\hline have sex & $<1-4$ & 1 & 1 & $<1-8$ & 3.5 & 2 \\
\hline \multicolumn{7}{|l|}{ sports } \\
\hline walking & $<1-4$ & 2 & 2 & $<1-6$ & 3 & 3 \\
\hline jogging & $<1-6$ & 4 & 3 & $<1-12$ & 5 & 4 \\
\hline breaststroke & $1-8$ & 4 & 4 & $2-12$ & 6 & 6 \\
\hline crawl & $1-8$ & 4 & 4 & $2-12$ & 6 & 6 \\
\hline dive & $4-26$ & 8 & $12^{\mathrm{E}}$ & $6-\emptyset$ & 12 & $12^{\mathrm{E}}$ \\
\hline tennis & $<1-8$ & 4 & 4 & $4-12$ & 7 & 6 \\
\hline soccer & $<1-8$ & 4 & $4^{\mathrm{F}}$ & $4-12$ & 8 & $8^{\mathrm{F}}$ \\
\hline competitive sp & $4-12$ & 6 & 6 & $6-12$ & 12 & 10 \\
\hline \multicolumn{7}{|c|}{ occupation $(8 \mathrm{~h} / \mathrm{d})$} \\
\hline mental demands & $<1-3$ & 1.5 & 2 & $<1-4$ & 2 & 3 \\
\hline physical work & $<1-6$ & 3.5 & $4^{\mathrm{A}}$ & $2-12$ & 6 & $6^{\mathrm{A}}$ \\
\hline \multicolumn{7}{|c|}{$\begin{array}{l}\text { Alonger in case of intraoperative CSF leak (see text). Bstarting point for gradual increase in activity (see text). Cexclusion of intracranial air provided, } \\
\text { e. g. by CT. Dprovided hyponatremia is ruled out and patient feels well (see text). Estatement of responsible surgeon mandatory. Fno headers. } \\
\text { Gprovided brain surface not involved by tumor or resection. } \emptyset=\text { never; The recommendations indicate the minimum time interval [weeks] after } \\
\text { surgery, when a specific activity may be resumed. The authors emphasize that the ability to resume such activities is also dependent on endocrino- } \\
\text { logical, neurological, ophthalmological, and mental state postoperatively. For details see text. }\end{array}$} \\
\hline
\end{tabular}




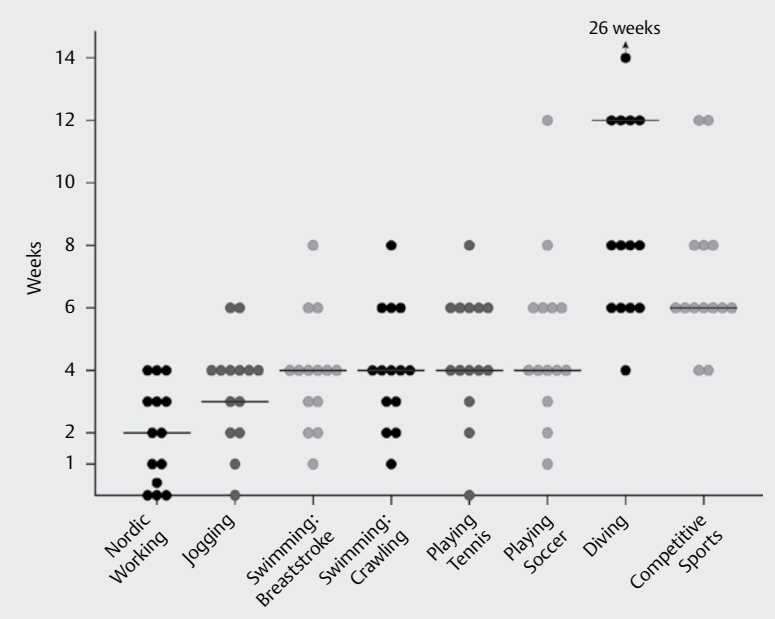

Fig. 2 The expert opinions of 14 German pituitary surgeons about postoperative sports activities following a routine transsphenoidal procedure are shown. The postoperative time interval after which sports activities can be resumed is depicted $(\bullet$ individual answer, - final consensus recommendation).

crucial point for this recommendation is whether an intraoperative CSF-leak was evident or not (see discussion).

Having sexual intercourse was considered by the pituitary surgeons to be permissible after a few days to 4 weeks postoperatively (median 1 week).

\section{Sports (see $>$ Fig. 2)}

Most pituitary surgeons allow leisure sports approximately 4 weeks after surgery: Nordic walking after a few days to 4 weeks (median 2 weeks). Jogging after a few days to 6 weeks (median 4 weeks). Swimming (breaststroke) after 1 to 8 weeks (median 4 weeks). Crawling after 1 to 8 weeks (median 4 weeks). Playing tennis after a few days to 8 weeks (median 4 weeks). Playing soccer after 1 to 8 weeks (median 4 weeks). This median values were confirmed as recommendations during discussion, except for jogging (recommendation 3 weeks). However, during soccer headers should be omitted for 12 weeks.

Heterogeneous opinions existed for scuba diving. Primary recommendations varied between 4 and 26 weeks (median 8 weeks). After interviews with experts for diving medicine, evaluation of relevant literature, and discussion between the authors, it is recommended not to dive earlier than 12 weeks after surgery (see discussion below).

According to the surgeons, competitive sports are allowed between 4 and 12 weeks after surgery (median 6 weeks). The final consent is to resume competitive sports not earlier than 6 weeks after surgery.

\section{Working life (see $>$ Fig. 3 )}

Occupation ( $8 \mathrm{~h}$ per day) with mental demands was considered feasible immediately after surgery to 3 weeks postoperatively (median 1.5 weeks). A consensus of 2 weeks was worked out.

The postoperative time interval for continuation of an occupation with physical labor varied between a few days and 6 weeks (me-

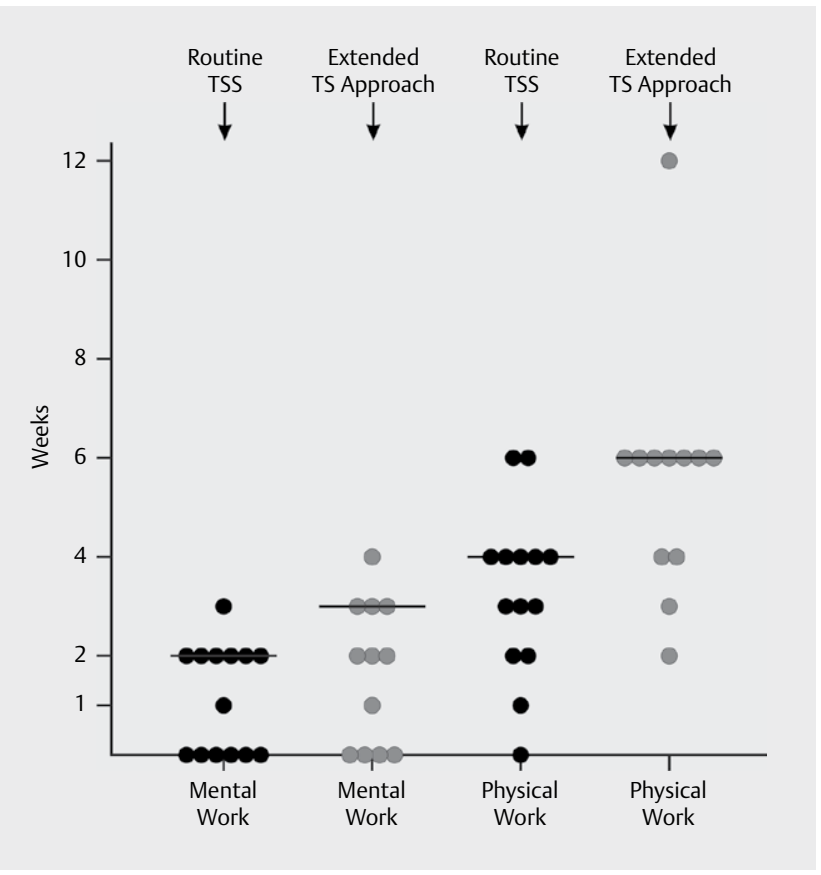

Fig. 3 The expert opinions of 14 German pituitary surgeons about work life following a routine or extended transsphenoidal procedure are shown. The postoperative time interval after which full-time work life can be resumed is depicted ( $\bullet$ individual answer, - final consensus recommendation).

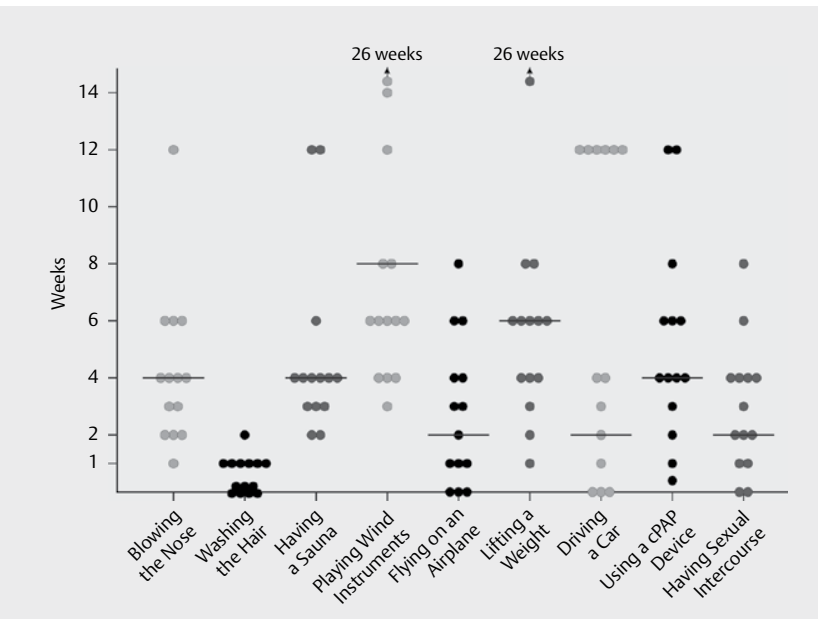

-Fig. 4 The expert opinions of 14 German pituitary surgeons about postoperative sports activities following an extended transsphenoidal procedure are shown. The postoperative time interval after which various daily activities can be resumed is depicted (• individual answer, - final consensus recommendation).

dian 3.5 weeks), recommendation is 4 weeks. The authors want to emphasize that these recommendations consider the operative approach only. Fitness for work is also dependent on endocrinological, neurological, ophthalmological, and mental state postoperatively. 


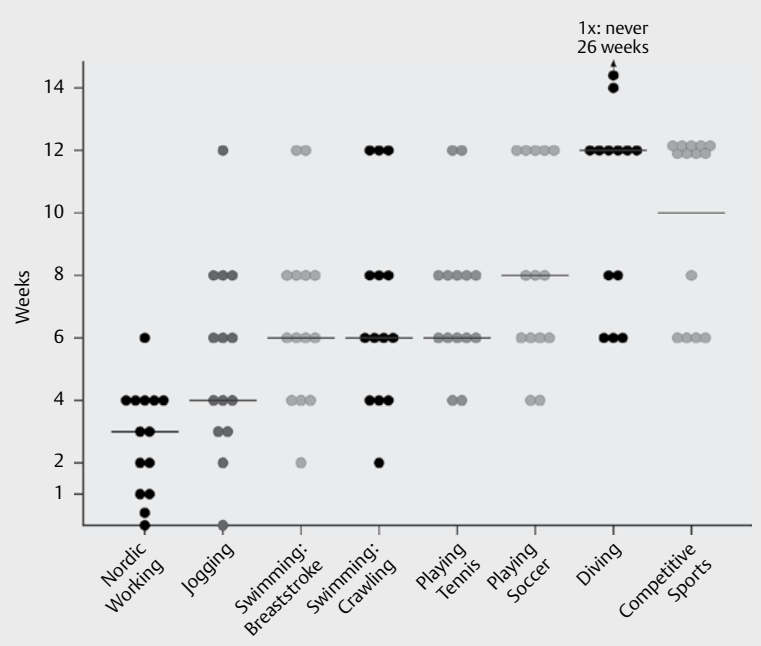

- Fig. 5 The expert opinions of 14 German pituitary surgeons about postoperative sports activities following a routine transsphenoidal procedure are shown. The postoperative time interval after which sports activities can be resumed is depicted ( $\bullet$ individual answer, - final consensus recommendation).

\section{Recommendations after extended transsphenoidal approach (see $>$ Fig. 3-5)}

For an extended transsphenoidal approach, the time interval until activities can be resumed was roughly twice as long compared to the routine approach.

Driving a car was allowed within the first 4 weeks after surgery by some pituitary surgeons, while other surgeons allow driving only after 3 months as it is recommended for patients with intracranial surgery. Discussion revealed that involvement of the brain (other than the optic nerves) is the crucial point to adjust the recommendations to routine instructions after transcranial operations.

Scuba diving cannot be resumed earlier than 12 weeks after surgery. The risk of scuba diving was considered particularly high as it is able to exert a tremendous increase of pressure to the area of skull base closure. The estimation of this construct`s stability provided by the responsible surgeon has to be the mainstay of recommendation in these cases. If concerns regarding the stability of skull base reconstruction exist scuba diving cannot be resumed.

The data and recommendations for both the routine and the extended approach are summarized in > Table 1.

\section{Discussion}

So far, no generally accepted guidelines for patient behavior following TSS exist in order to avoid postoperative complications. This survey aimed at giving an overview of the current status quo of recommendations in Germany and to find a consensus between pituitary surgeons after a focused literature review. This led to a proposal of guidelines. Although a wide variance of individual statements, which can be explained by missing guidelines, was observed initially, through the process described here a consensus was suggested by the authors and approved by all participants.

\section{Wound healing after TSS}

Mucosal tissue healing is divided into four stages - exsudative (minutes to hours), resorptive (up to 3 days), proliferative (up to 7 days), and regenerative (several months) [8]. The extent of mucosal injury is crucial to the required time to heal. Xu and co-authors [9] reported, that after functional endoscopic sinus surgery the reepithelialization is completed within 10 weeks in the majority of patients, however, few patients needed longer than 15 weeks. Regarding mucociliary transport, Shaw et al. [10] reported a functional alteration of more than 3 months in an animal model. Injury to the periost, which regularly happens in pituitary surgery, leads to osteoneogenesis. In an animal model an increase of osteogenesis up to a year after surgery was reported [11], therefore showing incomplete healing during that time. Taking this limited data into account, most activities seem to be safe after a few weeks regarding potential wound healing complications, except for scuba diving after extended approaches, which have to be carefully evaluated.

\section{Valsalva maneuver (raised intracranial pressure)}

Performing valsalva maneuver means elevated intrathoracal pressure with closed vocal cords and consecutive rise of intracranial pressure through reduction of intracranial venous outflow $[12,13]$. Increased intracranial pressure raises the risk of CSF-fistula after TSS. Therefore, careful consideration should be given to this issue in the postoperative period [14-16]. This mechanism seems to be relevant for recommendations concerning lifting heavy weights, having sex, playing tennis and soccer.

\section{Sexual intercourse}

The advice concerning the resumption of sexual activity should address the avoidance of valsava maneuver, straining, heavy lifting, and pressure on the abdomen in case of intraoperative CSF leak, which implies advice concerning sexual practice [17].

\section{Playing wind instruments}

When playing wind instruments, valsava maneuver seems also to be applicable, as the outflow resistance of the instrument will also elevate the thoracal pressure. The pressure in the sphenoid sinus itself should not be a problem in this activity, as the closure of soft palate permits a barrier against elevated pressure in the nasal cavity and paranasal sinus. The recommendation of the consultant is to start playing wind instruments not earlier than 6 weeks after transsphenoidal surgery with low pressure for short playing periods (e. g. 10 min. 3 times a day), gradually intensifying the activity by 30 to $60 \mathrm{~min}$. per week, until full load is reached.

\section{Concussion}

In soccer, as in any other contact sports, concussion may also be a mechanism which could lead to postoperative complications. For the same reason headers during playing soccer should be omitted for at least 3 months after TSS.

\section{Raised pressure in paranasal sinuses}

Blowing one's nose, using a CPAP-device, and scuba diving are associated with elevated pressure in paranasal sinus and an inversed pressure gradient compared to the state of valsalva maneuver. Air 
could be forced through the operative defect and cause tension pneumencephalus $[18,19]$, for which untreated obstructive sleep apnea, cerebrospinal fluid leaks, postoperative positive-pressure mask ventilation, large pituitary tumors, and intraoperative lumbar drainage catheters were reported as risk factors [20]. Therefore, recommendations to resume these activities not only depend on the extent of the approach (routine vs. extended), but also on the occurrence of intraoperative CSF-leak during routine procedures.

\section{CPAP}

Obstructive sleep apnea (OSA) is frequent in patients with pituitary disorder: Particularly in acromegaly, OSA is a frequent presenting symptom, and can be resolved by successful TSS [21]. Many patients with OSA are treated by using a CPAP-device. Affected patients benefit from the use of CPAP or bilevel positive airway pressure (BiPAP) after any kind of surgical procedures. However, both methods could cause pneumocephalus after TSS [22,23]. Unless contraindicated by the surgical procedure, the use of CPAP-device early after surgery is generally recommended if it was already used by the patients preoperatively [24, 25]. However, currently no consensus exists for the management of OSA patients undergoing transsphenoidal operations [26]. In a series of 469 patients undergoing TSS, 105 were at risk for OSA, and 10 of them developed postoperative hypoxemia which was treated with low-flow oxygen using face mask. However, three of them required a CPAP device not earlier than 2 days after surgery. None of them had an intraoperative CSF-leak, and no complications occurred after application of CPAP [27]. In another retrospective review the use of CPAP was re-initiated in 25 of 323 patients undergoing 349 TSS early after surgery. The only 2 cases with postoperative pneumocephalus in this series did not belong to the subgroup using CPAP postoperatively, leading these authors to the assumption that resuming CPAP early after TSS might be less dangerous than previously stated [28].

\section{Diving}

While pituitary surgeons are often faced with patients using a CPAP-device for treatment of OSA, the question when to resume scuba diving after TSS is asked rarely. This may explain the diversity of pituitary surgeons ` primary statements in this survey. Moreover, only one of the authors has personal experience with scuba diving. Therefore, the authors included the advice of several consultants for diving medicine especially for this topic. Diving at the surface using a snorkel is supposed to be equivalent to crawling. In greater depth problems with pressure gradients may occur between solid tissues and gas containing cavities, such as sinuses. Normal pressure at the sea level is 1 bar. Air in a diver's body air spaces will be compressed as pressure increases and expand as pressure decreases. During scuba dive descending leads to a linear pressure increase ( 1 bar per 10 meter depth). Diving at $10 \mathrm{~m}$ depth means a pressure increase of 1 bar and an absolute pressure of 2 bars (relative change of $100 \%$ ). As a consequence, any gas volume in the body is compressed to the half of its initial volume, thus producing a negative pressure gradient in case of entrapment. In scuba diving any communicating gas compartment is equilibrated to ambient pressure. Therefore, no pressure gradients will develop. Thus, the problems with pressure gradients in scuba diving arise only with trapped air compartments, wherever they may be. In apnea diving (breathhold diving) by definition any air filled compartments are enclosed air compartments unless flooded and therefore location of relevant pressure gradients.

The pressure in the paranasal sinus and middle ear rises if the gas cannot escape properly. TSS is associated with swelling of the nasal mucosa and impairs ventilation of the middle ear through the Eustachian tube and of the paranasal sinuses. In a retrospective cohort of 306 divers, who were treated by otorhinolarnyngologists, $46 \%$ had problems with the middle ear, $18 \%$ with the inner ear, and $17 \%$ with the nose and sinuses [29]. Sinus barotrauma from scuba diving is self-limiting in almost all cases, and frequently results from nasal pathology [30,31]. Two of the consultants argued, that as long as a normal outflow of gas from the paranasal sinuses is given, there should be no pressure gradient between this and the sella or the cranial cavity, which would allow diving even with incomplete bony closure after 3 months or 6 months, respectively. On the other hand it has been claimed recently, that sphenoid sinus barotrauma may be underreported and misdiagnosed [32], and limitation of local ventilation may be overlooked. After sphenoid sinus barotrauma sinusitis and abscess formation [33], intrasellar air collection [34] and even subarachnoid pneumatocephalus with severe persistent neurological deficit [35] have been reported. The latter two cases showed spontaneous bony defects of the sphenoidal wall, which may be equivalent to the postoperative state after TSS in many cases. In conclusion, after surgeon 's statement on the stability of the skull base scar, postoperative sinusitis especially of the sphenoid sinus and any trapped air should be ruled out by ENT physicians before scuba diving is resumed after TSS. However, ambitious apnoe diving with persistent bony defect of the skull base should be omitted lifelong.

\section{Flying on an airplane}

Barometric changes also play a role in the question regarding the recommendation to resume flying on an airplane [36, 37]. At a height of $10.000 \mathrm{~m}$, the air pressure is approximately $1 / 4$ of the pressure on ground. However, the cabin pressure appears to be unproblematic. According to Lufthansa, the maximum cabin pressure in an aircraft corresponds to the pressure in a height of approximately $2500 \mathrm{~m}$ (depending on aircraft type cabin pressure can be lower). Nasal swelling could impair ventilation of the paranasal sinuses and middle ear after TSS and make flying painful. While air can more easily escape from the sinuses or the middle ear during ascent of an aircraft even if the mucosa is swollen, the flow of air into the paranasal sinuses during descent and landing is more problematic and can cause heavy pain.

Our permission to resume flying in an aircraft as early as one week after surgery definitely requires the exclusion of intracranial air by CT or MRI in order to prevent space-occupying pneumatocephalus. Particular attention is required following an extended transsphenoidal approach.

\section{Risk of cerebral fits}

\section{Driving a motor vehicle}

The recommendation to resume driving a car as early as 5 days after TSS in uncomplicated cases without any involvement of brain surface by tumor or surgery seems to be applicable when the patient feels well, has neither neurological nor ophthalmological deficit, 
and hyponatremia is ruled out. One has to keep in mind and instruct the patient, that the latter may also occur in the second week after TSS and even later, and may cause seizures [38-41]. It is very important to instruct the patient that in case of secondary malaise after discharge, driving a motor vehicle is prohibited. In case of postoperative seizures fitness to drive is assessed according to neurological standards.

If extended TSS involves brain tissue, driving a car is not allowed for 3 months according to the regulations following craniotomy.

\section{Mental and physical condition}

\section{Work live}

The recommendations concerning resumption of work life in this manuscript focus on the operative approach and its consequences only. Any neurological and ophthalmological problem may profoundly change the advices given. The same is true for the endocrinological state. In Cushing's disease or acromegaly, the co-morbidities could represent a limitation to resume work after TSS.

\section{Conclusions}

Despite the diversity of opinions, the audit provides important information on expert opinions and their customs in patients' counselling with the power of about 1.000 transsphenoidal procedures performed per year. Together with information from the meaningful literature the data of our survey provide a basis for elaboration of joint recommendations for patients' conduct and to minimize the approach-related postoperative risks after TSS.

\section{Acknowledgements}

Further participating neurosurgeons: Martin Bettag, Trier, Marcus Czabanka, Berlin, Christian Ewelt, Münster, Andreas Jödicke, Berlin, Jürgen Kreutzer, Nürnberg, Walter Rachinger, München, Mukesch Johannes Shah, Freiburg, Peter Vajkoczy, Berlin, Germany.

Participating consultants: Eckhart Altenmüller, professor for music physiology and musician's medicine, Hannover, Julian Brade, neurosurgeon, Minden, Helmut Landgraf, professor for aviation medicine, Berlin, Tim Christopher Lendzian, anesthesiologist, Bünde, Claus-Martin Muth, professor for anesthesiology, Ulm, Peter Schellinger, professor for neurology, Minden, Martin Schrader, professor for otorhinolaryngology, Minden, Hendrik Schröder, industrial medicine and diving medicine consultant, Minden, Ulrich Van Laak, diving and hyperbaric medicine consultant GTÜM/EDTC/ ECHM, Kronshagen, Germany.

\section{Funding}

This research did not receive any specific grant from any funding agency in the public, commercial or not-for-profit sector.

\section{Conflict of Interest}

No conflict of interest has been declared by the authors.

\section{References}

[1] Hardy J. Transsphenoidal microsurgery of the normal and pathological pituitary. Clin Neurosurg 1969; 16: 185-217

[2] Cappabianca P, Cavallo LM, de Divitiis E. Endoscopic endonasal surgery. Neurosurgery 2004; 55: 933-941

[3] Mortini P, Losa M, Barzaghi R et al. Results of transsphenoidal surgery in a large series of patients with pituitary adenoma. Neurosurgery 2005; 56: 1222-1233

[4] Honegger J, Schmalisch K, Beuschlein F et al. Contemporary microsurgical concept for the treatment of Cushing 's disease: Endocrine outcome in 83 consecutive patients. Clin Endocrinol (Oxf) 2012; 76: 560-567

[5] Ciric I, Ragin A, Baumgartner C et al. Complications of transsphenoidal surgery: Results of a national survey, review of literature, and personal experience. Neurosurgery 1997; 40: 225-237

[6] Cote D], Dasenbrock HH, Muskens IS et al. Readmission and other adverse events after transsphenoidal surgery: Prevalence, timing, and predictive factors. J Am Coll Surg 2017; 224: 971-979

[7] Brouwers MC, Kerkvliet K, Spithoff K. The AGREE reporting checklist: A tool to improve reporting of clinical practice guidelines. BMJ 2016; 352: i1152

[8] Beule AG, Hosemann W. [Wound healing after endoscopic sinus surgery and postoperative management]. HNO 2009; 57: 763-771

[9] Xu G, jiang $\mathrm{H}$, Li H et al. Stages of nasal mucosal transitional course after functional endoscopic sinus surgery and their clinical indications. ORL J Otorhinolaryngol Relat Spec 2008; 70: 118-123

[10] Shaw CK, Cowin A, Wormald PJ. A study of the normal temporal healing pattern and the mucociliary transport after endoscopic partial and full-thickness removal of nasal mucosa in sheep. Immunol Cell Biol 2001; 79: 145-148

[11] Rajapaksa SP, Ananda A, Cain TM et al. Frontal ostium neo-osteogenesis and restenosis after modified endoscopic Lothrop procedure in an animal model. Clin Otolaryngol Allied Sci 2004; 29: 386-388

[12] Mousavi SR, Fehlner A, Streitberger KJ et al. Measurement of in vivo cerebral volumetric strain induced by Valsalva maneuver. J Biomech 2014; 47: 1652-1657

[13] Zhang Z, Wang X, Jonas JB et al. Valsalva maneuver, intra-ocular pressure, cerebrospinal fluid pressure, optic disc topography: Beijing intracranial and intra-ocular pressure study. Acta Opthalmol 2014; 92: e475-e480

[14] Nath G, Korula G, Chandy M]. Effect of intrathecal saline injection and Valsalva maneuver on cerebral perfusion pressure during transsphenoidal surgery for pituitary macroadenoma. J Neurosurg Anesthesiol 1995; 7: 1-6

[15] Neville L, Egan RA. Frequency and amplitude of elevation of cerebrospinal fluid resting pressure by Valsalva maneuver. Can J Ophthalmol 2005; 40: 775-777

[16] Mishra SK, Mathew GA, Paul RR et al. Endoscopic repair of CSF rhinorrhea: An institutional experience. Iran J Otorhinolaryngol 2016; 28: $39-43$

[17] De Boisanger L, Kaliaperumal C. Sex after neurosurgery - is it safe? Neurosurgery 2018; 82: E67-E68

[18] Haran RP, Chandy MJ. Symptomatic pneumencephalus after transsphenoidal surgery. Surg Neurol 1997; 48: 575-578

[19] Satyarthee GD, Mahapatra AK. Tension pneumocephalus following transsphenoidal surgery for pituitary adenoma - report of two cases. J Clin Neurosci 2003; 10: 495-497

[20] Sawka AM, Aniszewski JP, Youn WF Jr et al. Tension pneomocranium, ar rare complication of transsphenoidal pituitary surgery: Mayo Clinic experience 1976 - 1998. J Clin Endocrinol Metab 1999; 84: 47314734 
[21] Sze L, Schmid C, Bloch KE et al. Effect of transsphenoidal surgery on sleep apnea in acromegaly. Eur J Endocrinol 2007; 156: 321-329

[22] Jarjour NN, Wilson P. Pneumocephalus associated with nasal continuous positive airway pressure in a patient with sleep apnea syndrome. Chest 1989; 96: 1425-1426

[23] Kopelovic JC, de la Garza G, Greenlee JDW et al. Pneumocephalus with BiPAP use after transsphenoidal surgery. J Clin Anesthesiol 2012; 24: 415-418

[24] American Society of Anesthesiologists. Practice guidelines for the perioperative management of patients with obstructive sleep apnea. A report by the American Society of Anesthesiologists Task Force on perioperative management of patients with obstructive sleep apnea. Anesthesiology 2006; 104: 1081-1093

[25] American Society of Anesthesiologists. Practice guidelines for the perioperative management of patients with obstructive sleep apnea. An update report by the American Society of Anesthesiologists task force on perioperative management of patients with obstructive sleep apnea. Anesthesiology 2014; 120: 268-286

[26] Venkatraghavan L, Perks A. Postoperative management of obstructive sleep apnea after transsphenoidal pituitary surgery. J Neurosurg Anesthesiol 2009; 21: 179-180

[27] Rahimi E, Mariappan R, Tharmaradinam S et al. Perioperative management and complications in patients with obstructive sleep apnea undergoing transsphenoidal surgery: Our institutional experience. J Anaesthesiol Clin Pharmacol 2014; 30: 351-354

[28] White-Dzuro GA, Maynard K, Zuckerman SL et al. Risk of post-operative in patients with obstructive sleep apnea undergoing transsphenoidal surgery. J Clin Neurosci 2016; 29: 25-28

[29] Klingmann C, Praetorius M, Baumann I et al. Otorhinolaryngologic disorder and diving accidents: An analysis of 306 divers. Eur Arch Otorhinolaryngol 2007; 264: 1243-1251

[30] Parell G], Becker GD. Neurological consequences of scuba diving with chronic sinusitis. Laryngoscope 2000; 110: 1358-1360
[31] Pennell D], Asimakopoulos P, Ram B et al. Periorbital emphysema after dive barotrauma without radiological evidence of paranasal sinus injury. Aviat Space Environ Med 2014; 85: 863-866

[32] Schipke JD, Cleveland S, Drees M. Sphenoid sinus barotrauma in diving: Case series and review of the literature. Res Sports Med 2018; 26: $124-137$

[33] Jeong JH, Kim K, Cho SH et al. Sphenoid sinus barotrauma after scuba diving. Am J Otolaryngol 2012; 33: 477-480

[34] Tryggvason G, Briem B, Guđmundsson Ó et al. Sphenoid sinus barotrauma with intracranial air in sella turcica after diving. Acta Radiol 2006; 8: 872-874

[35] Budal O, Risberg J, Troland K et al. Pneumocephalus, a rare complication of diving. Undersea Hyperb Med 2011; 38: 73-79

[36] Andersson N, Grip H, Lindvall P. Air transport of patients with intracranial air. computer model of pressure effects. Aviat Space Environ Med 2003; 74: 138-144

[37] Perin A, Larosa F, Longatti P. Barometric changes in patients with intracranial lesions: Can they dive and fly? Surg Neurol 2009; 71: 368-371

[38] Taylor SL, Tyrell JB, Wilson CB. Delayed onset hyponatremia after transsphenoidal surgery for pituitary adenomas. Neurosurgery 1995; 37: 649-653

[39] Atkin SL, Coady AM, White MC et al. Hyponatraemia secondary to cerebral salt wasting syndrome following routine pituitary surgery. Eur J Endocrinol 1996; 135: 245-247

[40] Boehnert M, Hensen J, Henig A et al. Severe hyponatremia after transsphenoidal surgery for pituitary adenoamas. Kidney Int Suppl 1998; 64: $12-14$

[41] Cuesta M, Hannon MJ, Thompson C]. Diagnosis and treatment of hyponatraemia in neurosurgical patients. Endocrinol Nutr 2016; 63: 230-238 


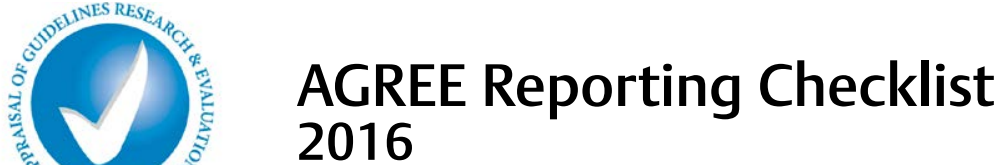

A G $\mathbf{R} \mathbf{E}$ This checklist is intended to guide the reporting of clinical practice guidelines.

REPORTING CHECKLIST

\section{CHECKLIST ITEM AND DESCRIPTION}

DOMAIN 1: SCOPE AND PURPOSE

\section{OBJECTIVES}

Report the overall objective(s) of the guideline. The expected health benefits from the guideline are to be specific to the clinical problem or health topic.

\section{QUESTIONS}

Report the health question(s) covered by the guideline, particularly for the key recommendations.

\section{POPULATION}

Describe the population (i.e., patients, public, etc.) to whom the guideline is meant to apply.

\section{DOMAIN 2: STAKEHOLDER INVOLVEMENT}

\section{GROUP MEMBERSHIP}

Report all individuals who were involved in the development process. This may include members of the steering group, the research team involved in selecting and reviewing/rating the evidence and individuals involved in formulating the final recommendations.

\section{TARGET POPULATION PREFERENCES AND VIEWS}

Report how the views and preferences of the target population were sought/considered and what the resulting outcomes were.

\section{TARGET USERS}

Report the target (or intended) users of the guideline.

\section{REPORTING CRITERIA}

Health intent(s) (Le., prevention, screening, diagnosis, treatment, etc.)

$\bigotimes$ Expected benefit(s) or outcome(s)

$\bigotimes$ Target(s) (e.g ., patient population, society)

Target population

Intervention(s) or exposure(s)

Comparisons (if appropriate)

Outcome(s)

Health care settinQ or context

Target population, sex and age

Clinical condition (if relevant)

Severity/stage of disease (if relevant)

Comorbidities (if relevant)

Excluded populations (if relevant) $\bigotimes$ Name of participant

$\bigotimes$ Discipline/content expertise (e.g., neurosurgeon, methodologist)

$\bigotimes$ Institution (e.g., St. Peter's hospital)

$\triangle$ Geographical location (e.g., Seattle, WA)

$\triangle$ A description of the member's role in the guideline development group

Statement of type of strategy used to capture patients'/publics' views and preferences (e.g., participation in the guideline development group, literature review of values and preferences)

$\bigotimes$ Methods by which preferences and views were sought (e .g., evidence from literature, surveys, focus groups)

$\square$ Outcomes/information gathered on patient/public information

$\bigotimes$ How the information gathered was used to inform the guideline development process and/or formation of the recommendations

The intended guideline audience (e.g. specialists, family physicians, patients, clinical or institutional leaders/admin istrators)

$\bigotimes$ How the guideline may be used by its target audience (e.g., to inform clinical decisions, to inform policy, to inform standards of care) 
DOMAIN 3: RIGOUR OF DEVELOPMENT

\section{SEARCH METHODS}

Report details of the strategy used to search for evidence. $\bigotimes$ Named electronic database(s) or evidence source(s) where the search was performed (e.g . MEDLINE, EMBASE, PsychiNFO, CINAHL)

$\square$ Time periods searched (e .g., January 1,2004 to March 31,2008)

$\square$ Search terms used (e.g ., text words, indexing terms, subheadings)

Full search strategy included (e.g., possibly located in appendix)

8. EVIDENCE SELECTION CRITERIA Report the criteria used to select (i.e., include and exclude) the evidence. Provide rationale, where appropriate.

Describe the strengths and limitations of the evidence. Consider from the perspective of the individual studies and the body of evidence aggregated across all the studies. Tools exist that can facilitate the reporting of this concept.

\section{FORMULATION OF RECOMMENDATIONS}

Describe the methods used to formulate the recommendations and how final decisions were reached. Specify any areas of disagreement and the methods used to resolve them.

$\bigotimes$ Target population (patient, public, etc.) characteristics

Study design

Comparisons (if relevant)

Outcomes

Language (if relevant)

Context (if relevant)

Study design(s) included in body of evidence

Study methodology limitations (sampling,

blinding, allocation concealment, analytical methods)

$\square$ Appropriateness/relevance of primary and secondary outcomes considered

Consistency of results across studies

Direction of results across studies

Magnitude of benefit versus magnitude of harm

Applicability to practice context

$\triangle$ Recommendation development process (e.g., steps used in modified Delphi technique, voting procedures that were considered) process (e.g. , extent to which consensus was reached using modified Delphi technique, outcome of voting procedures)

\section{STRENGTHS \& LIMITATIONS OF THE EVIDENCE}

$\triangle$ Outcomes of the recommendation development

How the process influenced the recommendations (e.g., results of Delphi technique influence final recommendation, alignment with recommendations and the final vote)

\section{CONSIDERATION OF BENEFITS AND HARMS}

Report the health benefits, side effects, and risks that were considered when formulating the recommendations.

\section{LINK BETWEEN}

RECOMMENDATIONS AND EVIDENCE

Describe the explicit link between the recommendations and the evidence on which they are based.
Supporting data and report of benefits

$\triangle$ Supporting data and report of harms/side effects/risks

$\square$ Reporting of the balance/trade-off between benefits and harms/side effects/risks

Recommendations reflect considerations of both benefits and harms/side effects/risks

How the guideline development group linked and $\quad$ n.a. used the evidence to inform recommendations

$\square$ Link between each recommendation and key evidence (text description and/or reference list) Link between recommendations and evidence summaries and/or evidence tables in the results section of the guideline 


\begin{tabular}{|c|c|c|}
\hline $\begin{array}{l}\text { 13. EXTERNAL REVIEW } \\
\text { Report the methodology used to conduct } \\
\text { the external review. }\end{array}$ & $\begin{array}{l}\square \text { Purpose and intent of the external review (e.g., } \\
\text { to improve quality, gather feedback on draft } \\
\text { recommendations, assess applicability and } \\
\text { feasibility, disseminate evidence) } \\
\square \text { Methods taken to undertake the external review } \\
\text { (e.g ., rating scale, open-ended questions) } \\
\square \text { Description of the external reviewers (e .g., } \\
\text { number, type of reviewers, affiliations) } \\
\square \text { Outcomes/information gathered from the external } \\
\text { review (e.g., summary of key findings) } \\
\square \text { How the information gathered was used to inform } \\
\text { the guideline development process and/or } \\
\text { formation of the recommendations (e.g., } \\
\text { guideline panel considered results of review in } \\
\text { forming final recommendations) }\end{array}$ & 3,11 \\
\hline $\begin{array}{l}\text { 14. UPDATING PROCEDURE } \\
\text { Describe the procedure for updating the } \\
\text { guideline. }\end{array}$ & $\begin{array}{l}\square \text { A statement that the guideline will be updated } \\
\square \text { Explicit time interval or explicit criteria to guide } \\
\text { decisions about when an update will occur } \\
\square \text { Methodology for the updating procedure }\end{array}$ & n.a. \\
\hline \multicolumn{3}{|l|}{ DOMAIN 4: CLARITY OF PRESENTATION } \\
\hline $\begin{array}{l}\text { 15. SPECIFIC AND UNAMBIGUOUS } \\
\text { RECOMMENDATIONS } \\
\text { Describe which options are appropriate in } \\
\text { which situations and in which population } \\
\text { groups, as informed by the body of } \\
\text { evidence. }\end{array}$ & $\begin{array}{l}\square \text { A statement of the recommended action } \\
\square \text { Intent or purpose of the recommended action } \\
\text { (e.g., to improve quality of life, to decrease side } \\
\text { effects) } \\
\square \text { Relevant population (e .g., patients, public) } \\
\square \text { Caveats or qualifying statements, if relevant } \\
\text { (e.g., patients or conditions for whom the } \\
\text { recommendations would not apply) } \\
\square \text { If there is uncertainty about the best care } \\
\text { option(s), the uncertainty should be stated in the } \\
\text { guideline }\end{array}$ & $2,3,8$ \\
\hline $\begin{array}{l}\text { 16. MANAGEMENT OPTIONS } \\
\text { Describe the different options for managing } \\
\text { the condition or health issue. }\end{array}$ & $\begin{array}{l}\square \text { Description of management options } \\
\square \text { Population or clinical situation most appropriate } \\
\text { to each option }\end{array}$ & $3-10$ \\
\hline $\begin{array}{l}\text { 17. IDENTIFIABLE KEY } \\
\text { RECOMMENDATIONS } \\
\text { Present the key recommendations so that } \\
\text { they are easy to identify. }\end{array}$ & $\begin{array}{l}\square \text { Recommendations in a summarized box, typed } \\
\text { in bold, underlined, or presented as flow charts } \\
\text { or algorithms } \\
\square \text { Specific recommendations grouped together in } \\
\text { one section }\end{array}$ & table \\
\hline \multicolumn{3}{|l|}{ DOMAIN 5: APPLICABILITY } \\
\hline $\begin{array}{l}\text { 18. FACILITATORS AND BARRIERS TO } \\
\text { APPLICATION } \\
\text { Describe the facilitators and barriers to the } \\
\text { guideline's application. }\end{array}$ & $\begin{array}{l}\square \text { Types of facilitators and barriers that were } \\
\text { considered } \\
\square \text { Methods by which information regarding the } \\
\text { facilitators and barriers to implementing } \\
\text { recommendations were sought (e.g., feedback } \\
\text { from key stakeholders, pilot testing of guidelines } \\
\text { before widespread implementation) } \\
\square \text { Information/description of the types of facilitators } \\
\text { and barriers that emerged from the inquiry (e.g., } \\
\text { practitioners have the skills to deliver the } \\
\text { recommended care, sufficient equipment is not } \\
\text { available to ensure all eligible members of the }\end{array}$ & n.a. \\
\hline
\end{tabular}




\begin{tabular}{|c|c|c|c|}
\hline & & $\begin{array}{l}\text { population receive mammography\} } \\
\text { How the information influenced the guideline } \\
\text { development process and/or formation of the } \\
\text { recommendations }\end{array}$ & \\
\hline $\begin{array}{l}\text { 19. IMPLEMENTATION ADVICE/TOOLS } \\
\text { Provide advice and/or tools on how the } \\
\text { recommendations can be applied in } \\
\text { practice. }\end{array}$ & 凶 & $\begin{array}{l}\text { Additional materials to support the } \\
\text { implementation of the guideline in practice. } \\
\text { For example: } \\
\text { O Guideline summary documents } \\
\text { O Links to check lists, algorithms } \\
0 \text { Links to how-to manuals } \\
\text { O Solutions linked to barrier analysis (see Item } \\
18 \text { ) } \\
\text { Tools to capitalize on guideline facilitators } \\
\text { (see Item 18) } \\
\text { Outcome of pilot test and lessons learned }\end{array}$ & table \\
\hline $\begin{array}{l}\text { 20. RESOURCE IMPLICATIONS } \\
\text { Describe any potential resource } \\
\text { implications of applying the } \\
\text { recommendations. }\end{array}$ & $\begin{array}{l}\square \\
\square \\
\square \\
\square\end{array}$ & $\begin{array}{l}\text { Types of cost information that were considered } \\
\text { (e.g., economic evaluations, drug acquisition } \\
\text { costs) } \\
\text { Methods by which the cost information was } \\
\text { sought (e.g ., a health economist was part of the } \\
\text { guideline development panel, use of health } \\
\text { technology assessments for specific drugs, etc.) } \\
\text { Information/description of the cost information } \\
\text { that emerged from the inquiry (e.g., specific drug } \\
\text { acquisition costs per treatment course) } \\
\text { How the information gathered was used to inform } \\
\text { the guideline development process and/or } \\
\text { formation of the recommendations }\end{array}$ & n.a. \\
\hline $\begin{array}{l}\text { 21. MONITORINGI AUDITING CRITERIA } \\
\text { Provide monitoring and/or auditing criteria } \\
\text { to measure the application of guideline } \\
\text { recommendations. }\end{array}$ & $\begin{array}{l}\square \\
\square \\
\square \\
\square\end{array}$ & $\begin{array}{l}\text { Criteria to assess guideline implementation or } \\
\text { adherence to recommendations } \\
\text { Criteria for assessing impact of implementing the } \\
\text { recommendations } \\
\text { Advice on the frequency and interval of } \\
\text { measurement } \\
\text { Operational definitions of how the criteria should } \\
\text { be measured }\end{array}$ & n.a. \\
\hline \multicolumn{4}{|l|}{ DOMAIN 6: EDITORIAL INDEPENDENCE } \\
\hline $\begin{array}{l}\text { 22. FUNDING BODY } \\
\text { Report the funding body's influence on the } \\
\text { content of the guideline. }\end{array}$ & $\square$ & $\begin{array}{l}\text { The name of the funding body or source of } \\
\text { funding (or explicit statement of no funding) } \\
\text { A statement that the funding body did not } \\
\text { influence the content of the guideline }\end{array}$ & n.a. \\
\hline $\begin{array}{l}\text { 23. COMPETING INTERESTS } \\
\text { Provide an explicit statement that all group } \\
\text { members have declared whether they have } \\
\text { any competing interests. }\end{array}$ & $\begin{array}{l}\square \\
\square \\
\square \\
\square\end{array}$ & $\begin{array}{l}\text { Types of competing interests considered } \\
\text { Methods by which potential competing interests } \\
\text { were sought } \\
\text { A description of the competing interests } \\
\text { How the competing interests influenced the } \\
\text { guideline process and development of } \\
\text { recommendations }\end{array}$ & $\begin{array}{l}\text { title } \\
\text { Page }\end{array}$ \\
\hline
\end{tabular}

From:

Brouwers MC, Kerkvliet K, Spithoff K, on behalf of the AGREE Next Steps Consortium. The AGREE Reporting Checklist: a tool to improve reporting of clinical practice guidelines. BMJ 2016;352:i1152. doi: 10.1136/bmj.i1152.

For more information about the AGREE Reporting Checklist, please visit the AGREE Enterprise website at http://www.agreetrust.org. 